\title{
Respiration Comes of Age
}

Dear Reader

By 'coming of age' I mean that as of this year the journal will appear monthly, which has been my aim for many years. For many years Respiration has had 1 volume of 6 issues per year. With the quick growth witnessed over the most recent years, we had increased our print volume, moving to 2 volumes of 4 issues each in both 2008 and 2009. As the upward trend in the number and quality of submissions continues, we can now move to monthly issues, i.e. 2 volumes of 6 issues each per year. This means that accepted articles will see print even faster. As quality remains our top priority, we will not strive to print more, but rather lower our acceptance rate to below $20 \%$ of the overall submission rate.

Another achievement worth mentioning here is the speed of the editorial team, i.e. our time from submission to first verdict to the authors, which currently stands at 3 weeks on average. This is indeed hard to beat and is shorter than for many top journals in the field. The people making this possible are the reviewers and associate editors of the journal, who by and large respect our request to review papers within 2 weeks. A big thank you to all of you, keep up the good work!

The scope of the journal will remain largely unchanged, with Respiration remaining a general respiratory journal. As mentioned previously, however, we would clearly like to attract more papers in the field of thoracic oncology. The reason for this is twofold: first, thoracic oncology is gaining more importance within the fraternity of respiratory physicians; i.e., the modern pulmonologist is increasingly involved in the multidisciplinary management of patients with thoracic malignancies. Fur- ther, Respiration is the home journal of the European Association of Bronchology and Interventional Pulmonology (EAB) with its dedicated section. Transthoracic, bronchoscopic, and thoracoscopic procedures, both of a diagnostic and therapeutic nature, represent an important part of the management of thoracic neoplasms. It is therefore a natural association to aim to publish more general papers in the area of thoracic oncology complementing the EAB's emphasis on invasive procedures. On that note I would also like to announce two important upcoming events for the Interventional Pulmonology scene, the 16th World Congress for Bronchology taking place in Budapest, Hungary (venue changed from Mannheim, Germany; the exact dates are still to be announced) and as a historic milestone, the 1st European Congress of Bronchology and Interventional Pulmonology provisionally planned in Marseille, France for March 2011.

In the journal's tradition we will also continue our popular section of the Thematic Review Series, usually a series of 4-6 related articles on one topic. For this first volume in 2010 the series is entitled: 'New Tools or Toys in Interventional Bronchoscopy' edited by Felix Herth, whose introductory note follows this editorial in the first issue. Our aim is to have one Thematic Review Series per volume, but due to increasing unsolicited demand we occasionally will have two concurrent series per issue.

Let me finish by reiterating the vision for the future of Respiration, which is to become one of the leading journals in respiratory medicine. Looking at what we have achieved so far, we are on our way there.

C.T. Bolliger, Editor-in-Chief, Cape Town

\section{KARGER}

Fax +41613061234

E-Mail karger@karger.ch

www.karger.com
(C) 2009 S. Karger AG, Basel

0025-7931/10/0791-0001\$26.00/0

Accessible online at:

www.karger.com/res 